\title{
Peptide Antibiotics Developed by Mimicking Natural Antimicrobial Peptides
}

Nihan Unubol ${ }^{1,2^{*}}$, Suleyman Selim Cinaroglu ${ }^{3}$, Merve Acikel Elmas ${ }^{4}$, Sümeyye Akçelik ${ }^{3}$, Arzu Tugba Ozal Ildeniz $^{5}$, Serap Arbak $^{4}$, Adil Allahverdiyev $^{1}$ and Tanil Kocagoz ${ }^{2,3^{*}}$

${ }^{1}$ Department of Bioengineering, Faculty of Chemistry and Metallurgy, Yildiz Technical University, Istanbul, Turkey

${ }^{2}$ Department of Medical Microbiology, School of Medicine, Acibadem University, Istanbul, Turkey

${ }^{3}$ Department of Medical Biotechnology, Institute of Health Sciences, Acibadem University, Istanbul, Turkey

${ }^{4}$ Department of Histology and Embryology, School of Medicine, Acibadem University, Istanbul, Turkey

${ }^{5}$ Department of Medical Engineering, Faculty of Engineering, Acibadem University, Istanbul, Turkey

"Corresponding author: Tanil Kocagoz, Department of Medical Microbiology, School of Medicine, Acibadem University, Istanbul, Turkey, Tel: +905323211784; E-mail: tanil.kocagoz@acibadem.edu.tr

Nihan Unubol, Department of Medical Microbiology, School of Medicine, Acibadem University, Istanbul, Turkey, E-mail: nihan.unubol@acibadem.edu.tr

Received date: July 07, 2017; Accepted date: August 3, 2017; Published date: August 7, 2017

Copyright: $\odot 2017$ Unubol N, et al. This is an open-access article distributed under the terms of the Creative Commons Attribution License, which permits unrestricted use, distribution, and reproduction in any medium, provided the original author and source are credited.

\begin{abstract}
Antimicrobial peptides are widely preferred drugs for infectious disease treatment. Inspired from natural antimicrobial peptides, short peptides showing good antibacterial activity are designed in this study. The peptides consisted of repeating hydrophobic and positively charged amino acids, positioned on one side of the alpha helix. Arginine in peptides resulted in better activity compared to lysine. Having positively charged amino acids at both ends, created better activity for Escherichia coli compared to Staphylococcus aureus, and only at one end, created comparable activities for both organisms. Positioning of arginines on one side in zigzag form prominently increased the activity compared to positioning on linear axis. Elongating hydrophobic tail resulted in self-binding and eliminated the antibacterial activity. Molecular dynamic simulations suggested that a single molecule is capable of creating hydrophilic channel in membrane. Electron microscopic examination of staphylococci treated with these peptides revealed that the bacteria split into halves. Docking studies revealed that the peptides strongly bind to the major peptidoglycan synthesizing membrane protein, glycosyltransferase. The unique composition and design of these peptides revealed a promising antibacterial activity that may further lead to the development of new antimicrobial compounds effective to multi-drug resistant organisms.
\end{abstract}

Keywords: Antimicrobial peptides; Peptide antibiotics; Cathelicidin

\section{Introduction}

Antimicrobial peptides (AMPs) are becoming a focus area for the emerging infectious diseases. They make up a large proportion of the natural immunity in a large group of organisms, from insects to humans. These are broad-spectrum antimicrobial peptides as a part of the cell-mediated immune system [1]. Most antimicrobial peptides (AMP) are stored in neutrophils and macrophage granules in animals and humans [2]. One of the most important common features of antimicrobial peptides is their amphophilic character, which is necessary for penetration into the membranes of pathogenic microorganisms. Additionally, the presence of negatively charged groups on bacterial membranes also creates electrostatic interaction with positively charged amphipathic groups of AMPs with the membranes. The hydrophilic site in the structure of AMP enables the peptide to align correctly in a pathogenic membrane $[3,4]$. With the alteration of the secondary and tertiary structures of the cathelicidins changes the vertical orientation so that they are buried in the lipid bilayer and creates pores in the membrane. The AMPs diffusing into the outer membrane of Gram-negative bacteria can pass through the peptidoglycan layer and the inner membrane to the cytoplasm of the bacterial cell, respectively [5]. Although AMPs have common features, they have several different activities. These include immunestimulation, antimicrobial activity and endotoxin neutralization [6]. The main advantages of antimicrobial peptides are their broad- spectrum efficiency, rapid action and low level of induced pathogen resistance. However, high costs of synthesis and susceptibility to proteases are their major disadvantages. Therefore, proteolytic susceptibility, $\mathrm{pH}$ sensitivity, their complex mode of action, decreased activity in physiological saline and serum and their production cost should be considered when developing AMPs to overcome their drawbacks [6-10].

Among AMPs, cathelicidins are members of a group of cationic peptides, a large group of molecules with amphipathic properties. Cathelicidins have a phylogenetically protected cathelin area [2]. Cathelicidins vary in amino acid sequence, and therefore in structure and size. They were first found in mammalian bone marrow myeloid cells and later in epithelial cells. Cathelicidins have two functional domains that allow them to exhibit both interspecies and intraspecies diversity. These are the N-terminal Cathepsin L inhibitor site and the C-terminal antimicrobial domain [11-14]. Cathelicidins are positively charged peptides that electrostatically interact with microorganisms that have negatively charged cell membranes such as bacteria, fungi and parasites by forming transmembrane pores in the cell membrane and directly kill microorganisms. Additionally, they inhibit bacterial biofilm formation and act as antiviral agents [15-24]. The cathelicidin mechanism of action, like other antimicrobial peptides, is in the form of disruption (damage and puncture) of cell membranes. Human cathelicidins do not act on healthy human cell membranes at physiological concentrations. It is suggested that the interaction of negatively charged lipid membranes with microorganisms and cationic 
peptides is due to direct, parallel adhesion, stabilization and neutralization of the membrane charge [25]. Human cathelicidin LL-37 is a representative member of the alpha helix family, and acts by disrupting bacterial membrane structure in three steps. First, the cationic peptide covers the anionic surface of the bacterial cell. Then, the helical structure in the amphipathic feature embeds itself in the membrane. Finally, it passes through the membrane, creating damage to the lipid bilayer and is connected parallel to the surface of the inner membrane as shown in the carpet model [1]. The peptide may disrupt the structure of the membrane by micellization at high concentrations. Alternatively, the peptide can take a vertical position to build up pores $[26,27]$. Only one cathelicidin protein which termed hCAP18 and Cathelicidin Related Antimicrobial Protein (CRAMP), are expressed in humans and mice, while in other species multiple cathelicidin peptides can be expressed $[28,29]$.

In this study, we designed cathelicidin like helical peptides by mimicking phylogenetically protected general sequences and structures of these cathelicidins yield better antibacterial activities compared to the antimicrobial peptides that exist in nature. With this promising peptide design, we have the potential to treat the emergent bacteria threats.

\section{Methods}

\section{Computional modelling}

The general structure of catelicidin-like peptides developed in this study were derived from conserved regions of human catelicidins which also show high homology with cathelicidins of many other organisms in nature. The amino acid sequences of catelicidins were obtained from NCBI. In the computational part, molecular dynamics (MD) simulations were carried out using the program NAMD 2.11 software [30] along with CHARMM27 all-atom force field [31] running in parallel on Intel Xeon multicore workstation. 3D structures of the peptides were constructed according to their amino acid sequences via PEP-FOLD3 server [32,33] with computed accuracy values greater than $99 \%$. One or more of these peptides were either embedded in or placed above membrane structures, which are constructed via VMD membrane plug-in version 1.1 [34]. To be consistent with the experiments, in order to mimic the bacterial membrane our membrane models were made up of 1-Palmitoyl-2oleoyl-sn-glycero-3-phosphoethanolamine (POPE) lipid molecules, which constitutes the major part of the bacterial ones. Furthermore, these starting structures were solvated with explicit TIP3P [35] water molecules, which had a margin of at least $10 \AA$ from any edge of the water to any membrane or peptide atom within a cubic simulation box. Then, all systems were neutralized by adding chloride ions. All of these steps were performed by Tcl commands embedded in VMD [34]. In the first simulation, everything except lipid tails was fixed. In this way, the appropriate disorder of a fluid-like bilayer was induced. In the second part, all systems were minimized for 1000 steps. Then, this was followed by equilibration run with the protein constrained. After minimization and protein-constrained equilibration, we proceeded by releasing the harmonic constraints and equilibrated the whole system for 2 ns. After the final equilibration, we performed further production runs for $2 \mathrm{~ns}$, with time steps of $2 \mathrm{fs}$. All trajectories were stored at every 2 ps for analysis. Throughout the simulations, long range electrostatic interactions were treated by Particle Mesh Ewald method (PME) [36,37], and truncation at $12 \AA$ cutoff distance and switch at 10 $\AA$ were applied for van der Waals interactions under periodic boundary conditions. All these NPT ensemble simulations were conducted at in silico correspondence of physiological conditions with temperature $310 \mathrm{~K}$ and under the normal pressure of $1 \mathrm{~atm}$, both controlled by Langevin dynamics. Throughout the analysis, to generate the radial distribution function plots we used Graphing Advanced Computation and Exploration (GRACE) program and for the snapshots Discovery Studio Visualizer version 16.1 [30] was used.

Besides the individual or self-clustered dynamic behavior of the designed peptides in water and/or membrane media, we were also interested in their dynamic interaction behavior with a certain membrane protein, especially which has vital function for the microorganisms. The protein chosen for this purpose was $S$. aureus membrane-bound glycosyltransferase molecule with a known three dimensional crystal structure (PDB code 3VMT) taken from the Protein Data Bank. In order to investigate this behavior, we have performed a molecular dynamics (MD) simulation of one of these well-performing peptides complexed with this membrane protein, which is attached on the top of the surface of the membrane. Prior to molecular dynamics simulation, during the preparation of the input structures, molecular docking was performed in order to find out the best binding positions of the peptides on the freely available surface of the protein, i.e. not in contact with the membrane. These docking simulations were performed by using a web-based service GRAMM-X [38], which is a widely accepted rigid-body protein-protein docking server, to predict the interactions between these kind of complexes computationally. The docking simulation of the peptide TN3 into the non-membrane-penetrating part of peptidoglycan glycosyltransferase structure was performed and 4 best non-overlapping docked positions out of this simulation were selected. Together with these 4 differently positioned TN3 peptides on the surface of the protein, 5 randomly positioned TN3 peptides, away from but close enough to sense the surface of the protein, were complexed with peptidoglycan glycosyltransferase to form the input structure for the molecular dynamics simulation. This 9-peptides-protein complex bound to POPE membrane model was simulated for a total of 4 ns within explicit water molecules by following the same procedures for the previous MD simulations.

\section{Peptide synthesis}

Designed peptides were synthesized by Metabion, Germany, according to clinical laboratory standards institute guidelines.

\section{Antimicrobial activity}

The minimal inhibitor concentrations (MIC) of the peptides were determined by microdilution assays.

\section{Hemolytic activity and cytotoxicity assays}

Hemolytic activity assays were carried out using human blood cells, using triton X-100 as lysis control agent. Cytotoxicity of AMPs was investigated by the sulforhodamine B (SRB assay G-Biosciences) using HeLa cells [39].

\section{Electron microscopy}

Detailed effects of AMPs on bacterial cells were investigated by transmission electron microscopy (TEM) (Jeol, Japan) [40]. 


\section{Fluorescent microscopy}

The penetration of SYBR Green dye through the membrane by the effect of AMPs, were investigated using fluorescent microscopy (Zeiss, Germany). For this purpose SYBR Green stock solution (Invitrogen, $A B D$ ) was diluted $1 / 500$ times as final concentration when preparing different concentrations of AMPs. The incubation time with AMPs was $15 \mathrm{~min}$ in these experiments before preparing smears.

The developed peptides were examined separately for their MIC concentrations using Proteinase $\mathrm{K}$ for protease activity.

\section{Results}

\section{Design, prediction and production of new antibacterials inspired from cathelicidins}

Peptides were designed by considering the structural properties of the shared homologous sequences between cathelicidins in the Cterminal region, which have been previously shown to be responsible of antimicrobial activity. We particularly tried to mimic the alpha helical structure, which has hydrophobic amino acids targeting the hydrophobic part of bacterial cell membrane phospholipids on one side and positively charged amino acids on the other side of the backbone. To create this structure, one positively charged amino acid was succeeded by two to four hydrophobic amino acids. For this purpose, we chose leucine (Leu), which has the longest hydorophobic side chain and arginine (Arg) with highest and largest positively charged side chain. We predicted that the hydrophobic part will be burried in the membrane, while, positively charged amino acids will interact with negatively charged phosphate groups of phospholipid membrane. Taking all these into consideration, we designed different peptides rich in Leu and Arg or lysine (Lys) (Table 1). While, Arg containing peptides had a pI between 12.4 and 12.6, TN2 which was the only Lys containing peptide, had a pI of 11.0. We used PEP-FOLD program [33] to estimate the three-dimensional structures of the molecules when designing the peptides. Synthetic peptides TN1-7 (Table 1) were obtained from Metabion, Germany.

\section{Antibacterial activity of the peptides}

We have selected $S$. aureus to represent gram positive cocci, E. coli and Klebsiella pneumonia ( $K$. pneumonia) for fermentative gram negative bacilli and Pseudomonas aeruginosa ( $P$. aeruginosa) for nonfermentative gram negative bacilli which are major pathogens of community acquired and hospital infections. Some of our newly designed peptides showed activity at lower concentrations than many antibiotics currently used. TN1, which contained arginine on each end, was the most effective AMP against E. coli and showed significant activities against all other tested organisms (Table 1). TN6, which contained one less Leu (in the middle) than TN1, showed 4 fold higher activity against $S$. aureus and 2 fold higher activity than $K$. pneumonia. TN3, which contained arginine on only one end showed better activity to $S$. aureus than $E$. coli, however, still maintained good activity against E. coli. TN4, which has 3 more leucine at the carboxy terminus compared to TN3, had no detectable activity on any of the organisms tested.

We suspected that elongating the hydrophobic tail may increase the self-interaction between the peptides and may inhibit their interaction with the membranes. Molecular dynamic modeling revealed that while 2 molecules of TN3 are joining together, it requires 4 molecules of TN4 for the similar self-interaction. TN5, which has one more Leu on each end compared to TN6, also did not show any significant activity. Compared to TN3, TN7 has one less Leu at the carboxy terminal revealed significantly lower activity. Changing arginines to lysines in TN2 compared to TN3 also lowered antibacterial activity significantly.

\section{Haemolytic activity and cytotoxicity}

The effects of TN AMPs on human red blood cells are shown in Figure 1. Triton-X 100 was used as a positive control for $100 \%$ hemolysis. When we assessed the hemolysis ratio of peptides to Triton $\mathrm{X} 100$, we observed that TN1, which has the best antibacterial effect on E. coli (MIC $2 \mu \mathrm{g} / \mathrm{ml}$ ), causes hemolysis in $50 \%$ of the cells (HC50) at $16 \mu \mathrm{g} / \mathrm{ml}$. TN3 and TN6, which showed significant activity to all species of bacteria tested, had an HC50 of $64 \mu \mathrm{g} / \mathrm{ml}$. Compared to LL-37, the MIC of TN1 was about 10 fold lower, while the HC50 was 10 times higher. For TN3 and TN6, the MIC was about 5 fold lower, while the HC50 was approximately 40 times higher than LL37, making safety index better than this natural AMP [1]. The hemolytic activity of TN1, TN2, TN3 and TN4 dropped rapidly after $64 \mu \mathrm{g} / \mathrm{ml}$ for TN1 and $128 \mu \mathrm{g} / \mathrm{ml}$ for the others. The cytotoxicity of AMPs to HeLa cells is shown in Figure 1. In general the cytotoxicity was lower than the hemolytic activity. The IC50 for TN1 was $128 \mu \mathrm{g} / \mathrm{ml}$ while its HC50 was $4 \mu \mathrm{g} / \mathrm{ml}$.

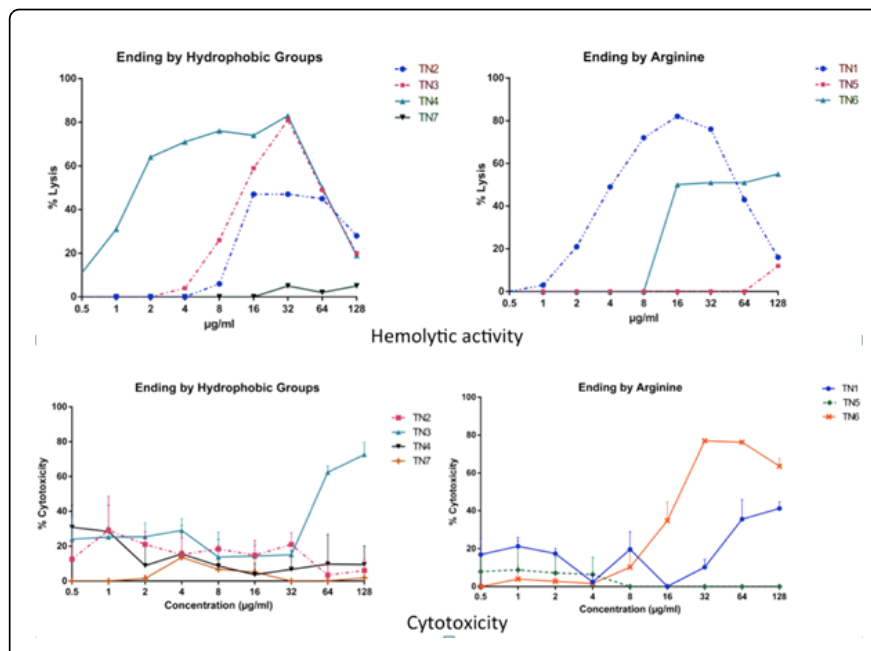

Figure 1: The hemolytic activity and cytotoxicity of AMPsHemolytic activity assays were used human blood cells by measuring the absorbance at $414 \mathrm{~nm}$. Cytotoxicity of AMPs were used HeLa cells by the sulforhodamine B (SRB assay GBiosciences).

\section{Transmission electron microscopic (TEM) investigation of AMPs effects on bacteria}

We investigated the effects of the AMPs TN1 on $S$. aureus with TEM, to understand their target in the cells. $S$. aureus cells were split in half incubation with $64 \mu \mathrm{g} / \mathrm{ml}$ of TN1 for $15 \mathrm{~min}$ (Figure 2). 


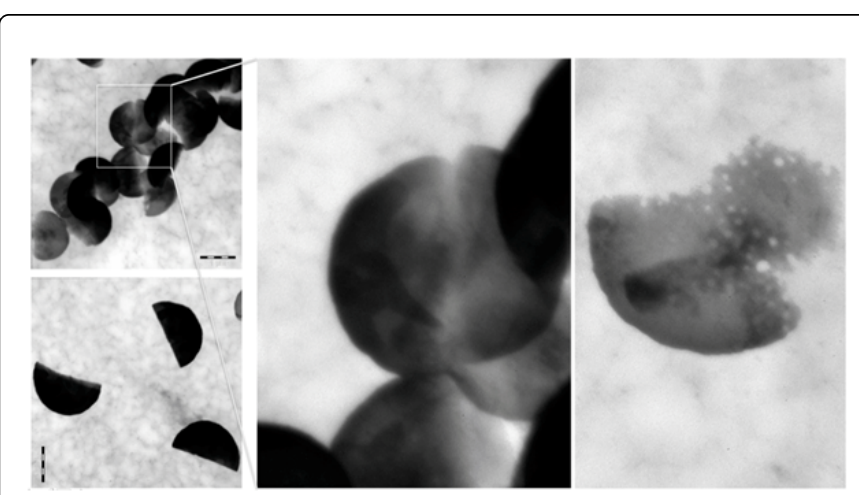

Figure 2: TEM investigation of AMPs effects on bacteria $S$. aureus pictures obtained by TEM showing the splitting of cells and damaging the membranes when treated with TN1.

\section{Fluorescent microscopic investigation of disruption of cell membrane}

It is known that the nucleic acid fluorescent dye SYBR green, does not rapidly penetrate through eucaryotic cell membrane [41]. When the membrane is disrupted, SYBR green rapidly enters the cell, binds to DNA starting to fluoresce under UV light. We have adapted this assay to bacterial cells to investigate the effect of the designed AMPs to bacterial cell membranes. When treated with SYBR green, intact bacteria did not stain. However, when treated with the AMPs, bacteria were stained, indicating the penetration of SYBR green and binding to DNA (Figure 3).
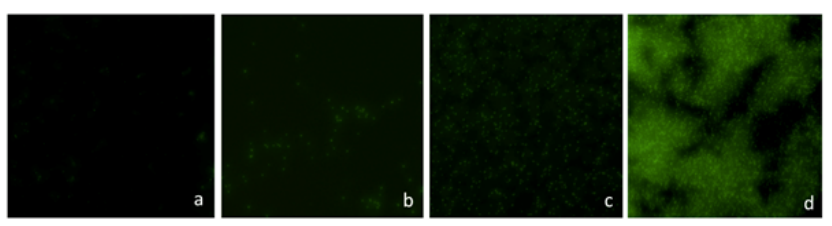

Figure 3: Penetration of SYBR Green dye by the effect of TN1 at different concentrations on $S$. aureus cells. (a) No peptide; cells are not visible since there is no penetration of dye and staining of DNA (b) TN1 $0.5 \mu \mathrm{g} / \mathrm{ml}$ (c) TN1 $2.0 \mu \mathrm{g} / \mathrm{ml}$ cells become visible by staining of their DNA (d) TN1 $4.0 \mu \mathrm{g} / \mathrm{ml}$ cells start to be lysed and probably released DNA can be seen outside the cells.

\section{Investigating the interaction of AMPs with bacterial membrane and membrane bound glycosyltransferase protein, by molecular dynamic simulations}

We have investigated the interaction of the most active AMPs, TN1 and TN3, by themselves, membrane lipids and TN3, membrane bound glycosyltransferase by molecular dynamics simulations. TN1 and TN3 integrated themselves into membrane lipids by pulling the negatively charged phosphate groups of the inner and outer side lipids by the positively charged Arg, which shrinked the membrane and decreased its original thickness (Figure 4).

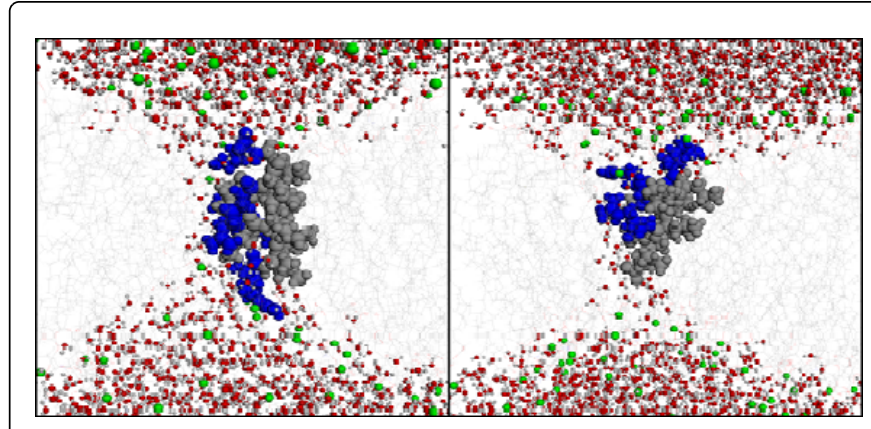

Figure 4: The interactions of TN1 (left) and TN3 (right) by the bacterial membrane. The membrane lipids are shown in light grey; water molecules red and white; phosphates green; arginines of the peptide blue; hydrophobic part dark grey.

They also created a hydrophilic channel between the charged groups, which allowed the free passage of water molecules, as well as hydrophilic molecules like SYBR green predicted by fluorescent microscopy data (Figure 3). Docking studies showed that TN3 bound strongly to active site of glycosyltransferase of $S$. aureus, the major enzyme responsible of building the cell wall peptidoglycan (Figure 5).

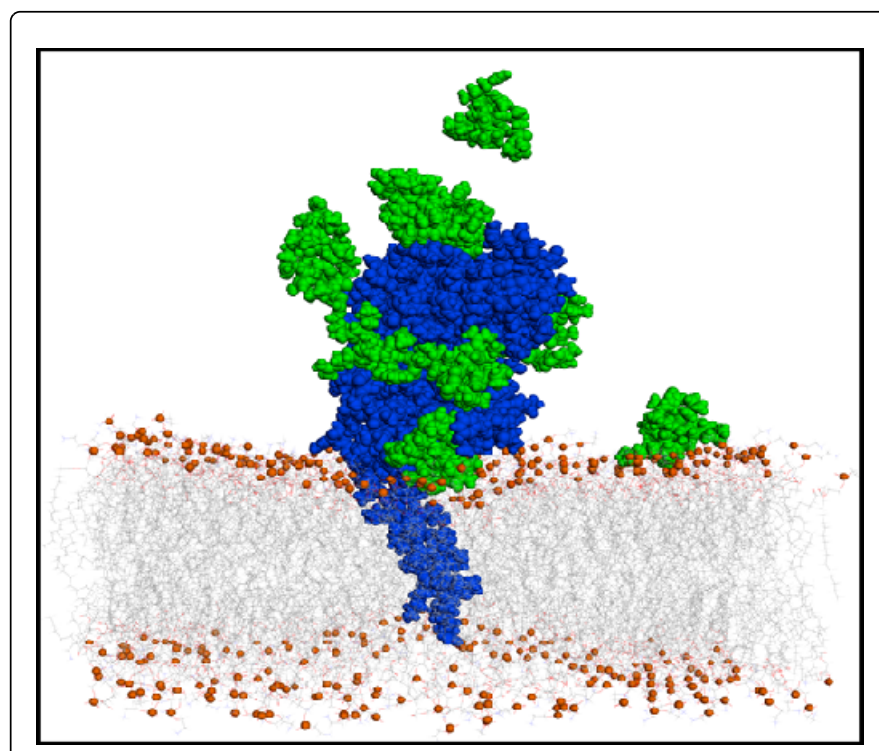

Figure 5: Binding of TN3 molecules to glycosyltransferase of $S$. aureus. Glycosyltransferase colored blue; TN3 molecules green; phosphates red.

\section{Discussion}

In recent years, global problem of increasing resistance to antimicrobials made impossible the treatment of many serious infections by antimicrobials. Drug companies lost their interest to develop new antimicrobials, since microorganisms develop resistance very quickly to these when they are started being used widely. There has been always an interest to develop antimicrobials that microorganisms cannot get resistant to them or at least it takes very long time until they get resistance. Natural peptide antibiotics are in fact antimicrobials of this kind. Although they are present in nature 
Page 5 of 6

since millions of years, they still show activity against many species of microorganisms. One of the reasons for that, maybe that peptide antibiotics mostly target cell membranes. Resistance, against antimicrobials, which target enzymes, develops quickly since a single mutation that changes the drug-binding site is usually sufficient for this. However, it is needed to modify lipids that make up the membranes in order to develop resistance to antimicrobials, which target membranes. This requires changing an important part of the pathway of the synthesis of membrane lipids. Even if such a change occurs in a microorganism, this is usually detrimental to the organism and the mutants probably either cannot survive this major change or lose their pathogenicity. For this reason, developing new AMPs may be an important way to fight with antimicrobial resistance.

We chose to develop catelicidin-like AMPs because of their simple structure, which makes easy to design and synthesize. Since the general structure of catelicidins consists of repeating positively charged amino acids separated by hydrophobic amino acids creating alpha helices which contain positively charged groups on one side of the helical backbone, we tried to design AMPs accordingly. Previously, Park et al. obtained the best activity with a peptide (named P5) which contained several repeating lysine and leucine, among all peptides they studied [42]. To understand the effect of using Lys or Arg, we designed TN2 and TN3 (Table 1), which are exactly the same except Lys present in TN2 were replaced by Arg in TN3. This change increased the antibacterial activity of the AMP by 4 - to 32 -fold in different species of bacteria while increasing the hemolytic activity only one fold. The hemolytic activity usually decreased at concentrations higher than 64 $\mu \mathrm{g} / \mathrm{ml}$. This may be due to exceeding the critical micelle concentration resulting in self-binding of AMPs that inhibits their binding to the cells. The cytotoxic activity on HeLa cells was usually lower than hemolytic activity. The IC50 (concentration that inhibited the growth of $50 \%$ of cells) of TN1 and TN3 which showed marked activity on bacteria, were 126 and $64 \mu \mathrm{g} / \mathrm{ml}$ respectively while their HC50 were 4 and $8 \mu \mathrm{g} / \mathrm{ml}$, respectively. The susceptibility of different cell types to AMPs should be taken into account when AMPs will be applied to different parts of the body for therapeutic use in the future.

Similarly, Wang et al. showed that a small 12 amino acid portion of catelicidin LL-37 showed significant antibacterial activity however replacing Arg by Lys decreased the activity [43]. We also investigated the positioning of positively charged amino acid on the helix by changing the number of Leu which changed the degree of turn from one positively charged amino acid to the other. TN5 which contained 3 Leu in between each Arg, positioned these at almost to a linear axis. When the number of Leu was decreased to 2 between the Arg at the end of molecule, positioning the Arg in a zigzag form on a linear axis, the activity increased more than one hundred times for $S$. aures and $E$. coli. Increasing the number of Leu in the middle of the molecule, from 3 as in TN6 to 4 in TN1, which resulted in the separation of two Arg in the middle from each other, increased the activity of the molecule two folds to $E$. coli while decreasing the activity in other species (Table 1). This may be due to different positioning of phosphate groups, which interact with Arg in different species of bacteria. Deleting the Arg from one end in TN3, turned the molecule into a three-branch corkscrew like structure which may ease the entrance of hydrophobic end without Arg, while the positively charged groups bind to phosphates. TN3 was one of the most active molecules among all the molecules we have designed. Decreasing one Leu from the hydrophobic end in TN7 decreased the activity significantly to all species of bacteria tested compared to TN3.

\begin{tabular}{|l|l|l|l|l|}
\hline $\begin{array}{l}\text { Antimicrobial } \\
\text { Peptides }\end{array}$ & $\begin{array}{l}\text { S. aureus } \\
\text { ATCC } \\
\mathbf{2 9 2 1 3}\end{array}$ & $\begin{array}{l}\text { E. coli } \\
\text { ATCC } \\
\mathbf{2 5 9 2 2}\end{array}$ & $\begin{array}{l}\text { K. pneumoniae } \\
\text { ATCC 10031 }\end{array}$ & $\begin{array}{l}\text { P. aeruginosa } \\
\text { ATCC 27853 }\end{array}$ \\
\hline $\begin{array}{l}\text { TN1: } \\
\text { RLLRLLLLRLLR }\end{array}$ & 16 & 2 & 16 & 16 \\
\hline TN2: KLLKLLKLLL & 64 & 16 & 512 & $>512$ \\
\hline TN3: RLLRLLRLLL & 8 & 4 & 16 & 16 \\
\hline $\begin{array}{l}\text { TN4: } \\
\text { RLLRLLRLLLLLL }\end{array}$ & $>512$ & $>512$ & 512 & 256 \\
\hline $\begin{array}{l}\text { TN5: } \\
\text { RLLLRLLLRLLLR }\end{array}$ & $>512$ & $>512$ & $>512$ & $>512$ \\
\hline TN6: RLLRLLLRLLR & 4 & 4 & 8 & 32 \\
\hline TN7: RLLRLLRLL & 256 & 64 & 256 & 64 \\
\hline
\end{tabular}

Table 1: Minimal Inhibitor Concentration $(\mu \mathrm{g} / \mathrm{ml})$ of TN AMPs (Patent pending).

TN AMPs hemolytic activity was usually much lower compared to their natural cathelicidin counterparts making their safety index better.

\section{Conclusion}

Developing peptide antimicrobials by mimicking natural antibiotics to microorganisms that rarely develop resistance, is an important way to fight with multi-drug resistant organisms. We have developed cathelicidin-like AMPs with a better safety index and better activity to microorganisms compared to their natural counterparts. Once their safety is proven by animal and human studies and made resistant to proteases, they may be important tools to treat infections caused by multi-drug resistant organisms. Our initial data revealed promising results for the efficacy of antimicrobial peptides against many clinically-relevant bacteria, which are the causative agents of serious human infections. We further plan to design new molecules with antimicrobial activities, and assess the efficacies of these molecules against other microorganisms. In conclusion, emerging bacterial diseases can be potentially treated with these novel antimicrobial peptides.

\section{References}

1. Oren Z, Lerman JC, Gudmundsson GH, Agerberth B, Shai Y (1999) Structure and organization of the human antimicrobial peptide LL-37 in phospholipid membranes: relevance to the molecular basis for its noncell-selective activity. Biochem J 341: 501-513.

2. Kosciuczuk EM, Lisowski P, Jarczak J, Strzalkowska N, Jozwik A, et al. (2012) Cathelicidins: family of antimicrobial peptides. A review. Mol Biol Rep 39: 10957-10970.

3. Andreu D, Rivas L (1998) Animal antimicrobial peptides: an overview. Biopolymers 47: 415-433.

4. White SH, Wimley WC, Selsted ME (1995) Structure, function, and membrane integration of defensins. Curr Opin Struct Biol 5: 521-527.

5. Hancock RE, Diamond G (2000) The role of cationic antimicrobial peptides in innate host defences Trends Microbiol 8: 402-410.

6. Gordon YJ, Romanowski EG, McDermott AM (2005) A review of antimicrobial peptides and their therapeutic potential as anti-infective drugs. Curr Eye Res 30: 505-515. 
7. Bagnicka E, Strzalkowska N, Jozwik A, Krzyzewski J, Horbanczuk J, et al. (2010) Expression and polymorphism of defensins in farm animals. Acta Biochim Pol 57: 487-497.

8. Meyerholz DK, Ackermann MR (2005) Antimicrobial peptides and surfactant proteins in ruminant respiratory tract disease. Vet Immunol Immunopathol 108: 91-96.

9. Sherman H, Chapnik N, Froy O (2006) Albumin and amino acids upregulate the expression of human beta-defensin 1. Mol Immunol 43: 1617-1623.

10. Koczulla AR, Bals R (2003) Antimicrobial peptides: current status and therapeutic potential. Drugs 63: 389-406.

11. Bals R, Wilson JM (2003) Cathelicidins--a family of multifunctional antimicrobial peptides. Cell Mol Life Sci 60: 711-720.

12. Zanetti M, Gennaro R, Romeo D (1995) Cathelicidins: a novel protein family with a common proregion and a variable C-terminal antimicrobial domain. FEBS Lett 374: 1-5.

13. Boman HG (1995) Peptide antibiotics and their role in innate immunity. Annu Rev Immunol 13: 61-92.

14. Zanetti M (2005) The role of cathelicidins in the innate host defenses of mammals. Curr Issues Mol Biol 7: 179-196.

15. Peel E, Cheng Y, Djordjevic JT, Fox S, Sorrell TC, et al. (2016) Cathelicidins in the Tasmanian devil (Sarcophilus harrisii). Scientific Rep 6: 35019 .

16. Overhage J, Campisano A, Bains M, Torfs EC, Rehm BH (2008) Hancock RE. Human host defense peptide LL-37 prevents bacterial biofilm formation. Infect Immun 76: 4176-4182.

17. Dean SN, Bishop BM, van Hoek ML (2011) Susceptibility of Pseudomonas aeruginosa Biofilm to Alpha-Helical Peptides: Denantiomer of LL-37. Front Microbiol 2: 128.

18. Amer LS, Bishop BM, van Hoek ML (2010) Antimicrobial and antibiofilm activity of cathelicidins and short, synthetic peptides against Francisella. Biochem Biophysical Res Commun 396: 246-251.

19. Murakami M, Lopez-Garcia B, Braff M, Dorschner RA, Gallo RL (2004) Postsecretory processing generates multiple cathelicidins for enhanced topical antimicrobial defense. J Immunol 172: 3070-3077.

20. Wong JH, Ng TB, Legowska A, Rolka K, Hui M, et al. (2011) Antifungal action of human cathelicidin fragment (LL13-37) on Candida albicans. Peptides 32: 1996-2002.

21. Barlow PG, Svoboda P, Mackellar A, Nash AA, York IA, et al. (2011) Antiviral activity and increased host defense against influenza infection elicited by the human cathelicidin LL-37. PloS one 6: e25333.

22. Howell MD, Jones JF, Kisich KO, Streib JE, Gallo RL, et al. (2004) Selective killing of vaccinia virus by LL-37: implications for eczema vaccinatum. J Immunol 172: 1763-1767.

23. Gordon YJ, Huang LC, Romanowski EG, Yates KA, Proske RJ, et al. (2005) Human cathelicidin (LL-37), a multifunctional peptide, is expressed by ocular surface epithelia and has potent antibacterial and antiviral activity. Curr Eye Res 30: 385-394.

24. Wong JH, Legowska A, Rolka K, Ng TB, Hui M, et al. (2011) Effects of cathelicidin and its fragments on three key enzymes of HIV-1. Peptides 32: 1117-1122.

25. Ramanathan B, Davis EG, Ross CR, Blecha F (2002) Cathelicidins: microbicidal activity, mechanisms of action, and roles in innate immunity. Microbes Infect 4: 361-372.
26. Lee CC, Sun Y, Qian S, Huang HW (2011) Transmembrane pores formed by human antimicrobial peptide LL-37. Biophys J 100: 1688-1696.

27. Wang G (2014) Human antimicrobial peptides and proteins. Pharmaceuticals (Basel) 7: 545-594.

28. Anderson RC, Rehders M, Yu PL (2008) Antimicrobial fragments of the pro-region of cathelicidins and other immune peptides. Biotechnol Lett 30: 813-818.

29. Vandamme D, Landuyt B, Luyten W, Schoofs L (2012) A comprehensive summary of LL-37, the factotum human cathelicidin peptide. Cell Immunol 280: 22-35.

30. Phillips JC, Braun R, Wang W, Gumbart J, Tajkhorshid E, et al. (2005) Scalable molecular dynamics with NAMD. J Comput Chem 26: 1781-1802.

31. Brooks BR, Brooks CL, MacKerell AD, Nilsson L, Petrella RJ, et al. (2009) CHARMM: The Biomolecular Simulation Program. J Comput Chem 30: 1545-1614.

32. Lamiable A, Thévenet P, Rey J, Vavrusa M, Derreumaux P, et al. (2016) PEP-FOLD3: faster de novo structure prediction for linear peptides in solution and in complex. Nucleic Acids Res 44: W449-W454.

33. Thévenet P, Shen Y, Maupetit J, Guyon F, Derreumaux P, et al. (2012) PEP-FOLD: an updated de novo structure prediction server for both linear and disulfide bonded cyclic peptides. Nucleic Acids Res 40: W288W293.

34. Humphrey W, Dalke A, Schulten K (1996) VMD: visual molecular dynamics. J Mol Graph 14: 33-38.

35. Jorgensen WL, Chandrasekhar J, Madura JD, Impey RW, Klein ML (1983) Comparison of simple potential functions for simulating liquid water. J Chem Phys 79: 926-935.

36. Cheatham TE III, Miller JL, Fox T, Darden TA, Kollman PA (1995) Molecular Dynamics Simulations on Solvated Biomolecular Systems: The Particle Mesh Ewald Method Leads to Stable Trajectories of DNA, RNA, and Proteins. J Am Chem Soc 117: 4193-4194.

37. Darden T, York D, Pedersen L, W DLS, W PJ, et al. (1993) Particle mesh Ewald: An $\mathrm{N} \log (\mathrm{N})$ method for Ewald sums in large systems. J Chem Phys 98: 10089-10092.

38. Tovchigrechko A, Vakser IA (2006) GRAMM-X public web server for protein-protein docking. Nucleic Acids Res 34: W310-W314.

39. Perez RP, Godwin AK, Handel LM, Hamilton TC (1993) Comparison of clonogenic, microtetrazolium and sulforhodamine $\mathrm{B}$ assays for determination of cisplatin cytotoxicity in human ovarian carcinoma cell lines. Eur J Cancer 29a: 395-399.

40. Hartmann M, Berditsch M, Hawecker J, Ardakani MF, Gerthsen D, et al. (2010) Damage of the Bacterial Cell Envelope by Antimicrobial Peptides Gramicidin S and PGLa as Revealed by Transmission and Scanning Electron Microscopy. Antimicrob Agents Chemother 2010: 3132-3142.

41. Feng J, Wang T, Zhang S, Shi W, Zhang Y (2014) An optimized SYBR Green I/PI assay for rapid viability assessment and antibiotic susceptibility testing for Borrelia burgdorferi. PloS one 9: e111809.

42. Park Y, Lee DG, Jang SH, Woo ER, Jeong HG, et al. (2003) A Leu-Lys-rich antimicrobial peptide: activity and mechanism. Biochim Biophys acta 1645: 172-182.

43. Wang G (2015) Improved methods for classification, prediction, and design of antimicrobial peptides. Methods Mol Biol 1268: 43-66. 